\title{
Right hemisphere learning disability associated with left hemisphere dysfunction: anomalous dominance and development
}

\author{
Thomas A Sandson, Dara S Manoach, Bruce H Price, Dorene Rentz, Sandra Weintraub
}

\begin{abstract}
Two patients are described with the social emotional processing disorder, a developmental syndrome usually ascribed to right hemisphere dysfunction. In these two patients however, neurological examinations, EEG, and neuroimaging studies were all consistent with left hemisphere dysfunction. Both patients were left handed and had findings suggestive of anomalous dominance for language. It is proposed that early left hemisphere injury may have resulted in functional reorganisation that allowed sparing of language and motor skills but interfered with the development of functions that the right hemisphere normally subserves.
\end{abstract}

$(\mathcal{F}$ Neurol Neurosurg Psychiatry 1994;57:1129-1132)

Many terms have been used to describe a developmental syndrome characterised by emotional and interpersonal difficulties, deficient paralinguistic communication, and impaired visuospatial and mathematical abilities relative to verbal skills. ${ }^{1-3} \mathrm{We}$ have referred to this syndrome as the social emotional processing disorder (SEPD). ${ }^{4}$ The SEPD has been associated with right hemisphere dysfunction based on the neuropsychological profile, neurological findings, and neurophysiological and neuroimaging studies. ${ }^{1-4}$ We now describe two left handed patients with the emotional, interpersonal, and cognitive features of SEPD and neurological, neurophysiological, and neuroanatomical evidence of early left hemisphere injury.

Neurology Unit, Beth

Israel Hospital and

Harvard Medical

School, Boston, MA,

USA

T A Sandson

D S Manoach

B H Price

D Rentz

$S$ Weintraub

Correspondence to:

Dr Sandson, Department of

Neurology, Beth Israel

Hospital, 330 Brookline

Ave, Boston, MA 02215

USA

Received 22 September 1993 and in final form

19 January 1994.

Accepted 7 February 1994 \section{She was an average student but needed tutor- ing in mathematics. Depression has been \\ CASE 1 \\ A 30 year old woman had developed high age. A right hemiparesis was first noted that time. At the age of 10 , she began to have recurrent complex partial seizures that were fractory to anticonvulsant medications. \\ She described herself as a shy, withdrawn, and socially isolated child with few friends.}

diagnosed since her early teens and has been unresponsive to psychotherapy and antidepressant medications.

On examination, she was shy, guarded, and easily embarrassed. She made little eye contact and speech prosody was flattened. Neuropsychological testing (table) showed a 19 point discrepancy between verbal IQ $\left(40^{\text {th }}\right.$ percentile) and performance IQ ( $8^{\text {th }}$ percentile) as measured by the WAIS-R. Attention was mildly impaired on tests of response inhibition and set maintenance such as the auditory Go-No go test and the Stroop colour interference test. Memory testing with the WMS-R showed a selective impairment of non-verbal memory. Language based functions were normal with the exception of below average performance on the Boston naming test. Many of the errors on the Boston naming test resulted from inaccurate perception of the stimulus picture. Visuospatial perceptual and constructional abilities were impaired. Tests of verbal reasoning and abstraction were performed well. She scored within the normal range on the Beck depression inventory. ${ }^{7}$

Neurological examination showed the ear and thumb to be smaller on the right than on the left. There was mild right upper motor neuron facial weakness. Rapid alternating movements and fine finger movements were slow and clumsy on the right. Deep tendon reflexes were increased on the right and stressed gait produced dystonic posturing of the right hand.

EEGs and EEG telemetry showed a left temporal seizure focus; MRI showed atrophy of the left temporal lobe and dilatation of the left temporal horn (figure).

On intracarotid amobarbitone testing, language and memory were entirely normal after the left internal carotid injection. There was no neglect on a random letter cancellation test. Right internal carotid injection resulted in unresponsiveness for the first 12 minutes, after which the EEG had returned to normal. When she awoke, she had mild left sided neglect on a random letter cancellation test.

A left temporal lobectomy was performed without complication. Pathology showed loss of large pyramidal neurons in the hippocampus and dentate gyrus with fibrillar astrocytosis. There have been no seizures since the surgery but emotional, interpersonal, and 
Neuropsychological data ${ }^{\star}$

\begin{tabular}{|c|c|c|c|c|}
\hline \multirow[b]{2}{*}{ WAIS-R } & \multicolumn{2}{|l|}{ Case 1} & \multicolumn{2}{|l|}{ Case 2} \\
\hline & $\begin{array}{l}\text { Verbal IQ } 98 \\
\text { Information } 10 \\
\text { Digit span } 10 \\
\text { Vocabulary } 10 \\
\text { Arithmetic } 11 \\
\text { Comprehension } 6 \\
\text { Similarities } 12\end{array}$ & $\begin{array}{l}\text { Performance IQ } 77 \\
\text { Picture completion } 6 \\
\text { Picture arrangement } 5 \\
\text { Block design } 6 \\
\text { Object assembly } 8 \\
\text { Digit symbol } 7\end{array}$ & $\begin{array}{l}\text { Verbal IQ } 108 \\
\text { Information } 13 \\
\text { Digit span } 11 \\
\text { Vocabulary } 13 \\
\text { Arithmetic } 11 \\
\text { Comprehension } 11 \\
\text { Similarities } 11\end{array}$ & $\begin{array}{l}\text { Performance IQ } 80 \\
\text { Picture completion } 8 \\
\text { Picture arrangement } 11 \\
\text { Block design } 5 \\
\text { Object assembly } 4 \\
\text { Digit symbol } 7\end{array}$ \\
\hline Shipley-Hartford & \multicolumn{2}{|c|}{$\begin{array}{l}\text { Vocabulary } 27 \\
\text { Abstraction } 38 \\
\text { Conceptual quotient } 123 \\
\text { Estimated IQ } 110\end{array}$} & \multicolumn{2}{|c|}{$\begin{array}{l}\text { Vocabulary } 30 \\
\text { Abstraction } 32 \\
\text { Conceptual quotient } 93 \\
\text { Estimated IQ } 111\end{array}$} \\
\hline $\begin{array}{l}\text { Wide range achievement } \\
\text { test: spelling }\end{array}$ & \multicolumn{2}{|c|}{$\begin{array}{l}\text { Standard score }=110 \\
75^{\mathrm{t}} \text { percentile } \\
\text { grade equivalent }>12\end{array}$} & \multicolumn{2}{|c|}{$\begin{array}{l}\text { Standard score }=111 \\
77^{\text {th }} \text { percentile } \\
\text { grade equivalent } 10.2\end{array}$} \\
\hline $\begin{array}{l}\text { Wide range achievement } \\
\text { test: reading }\end{array}$ & \multicolumn{2}{|c|}{$\begin{array}{l}\text { Standard score }=106 \\
66^{\text {th }} \text { percentile } \\
\text { grade equivalent }>12\end{array}$} & \multicolumn{2}{|c|}{$\begin{array}{l}\text { Standard score }=114 \\
82^{\text {nd }} \text { percentile } \\
\text { grade equivalent } 10.6\end{array}$} \\
\hline $\begin{array}{l}\text { Wide range achievement } \\
\text { test: arithmetic }\end{array}$ & \multicolumn{2}{|c|}{$\begin{array}{l}\text { Standard score }=101 \\
53^{\text {rd }} \text { percentile } \\
\text { grade equivalent 12B }\end{array}$} & \multicolumn{2}{|l|}{$\begin{array}{l}\text { Standard score }=92 \\
30^{\text {th }} \text { percentile } \\
\text { grade equivalent } 5.9\end{array}$} \\
\hline $\begin{array}{l}\text { Controlled oral word } \\
\text { association test F-A-S }\end{array}$ & \multicolumn{2}{|l|}{$32\left(29^{\text {th }}\right.$ percentile $)$} & \multicolumn{2}{|l|}{$42\left(69^{\text {th }}\right.$ percentile $)$} \\
\hline $\begin{array}{l}\text { Stroop colour interference } \\
\text { test ( } 50 \text { items) }\end{array}$ & \multicolumn{2}{|c|}{$\begin{array}{l}72 \text { seconds } \\
3 \text { errors of commission }\end{array}$} & \multicolumn{2}{|c|}{$\begin{array}{l}89 \text { seconds } \\
7 \text { errors of commission }\end{array}$} \\
\hline $\begin{array}{l}\text { Boston naming test } \\
\quad(\text { total }=60)\end{array}$ & \multicolumn{2}{|l|}{45} & \multicolumn{2}{|l|}{56} \\
\hline Wechsler memory scale & \multicolumn{2}{|c|}{$\begin{array}{l}\text { WMS-R: } \\
\text { Logical memory I 25/50 (47\%) } \\
\text { Logical memory II } 20 / 50(41 \%) \\
\text { Visual reproduction I } 35 / 41(65 \%) \\
\text { Visual reproduction II } 8 / 41(1 \%)\end{array}$} & \multicolumn{2}{|c|}{$\begin{array}{l}\text { WMS: } \\
\text { Logical memory } 18 / 23 \\
10 \text { minute delay } 17 / 23 \\
\text { Visual reproduction } 10 / 14 \\
10 \text { minute delay } 10 / 14\end{array}$} \\
\hline $\begin{array}{l}\text { Rey-Osterrieth complex } \\
\text { figure (total score }=36 \text { ) }\end{array}$ & \multicolumn{2}{|c|}{$\begin{array}{l}\text { Copy: } 36(99 \%) \\
\text { Immediate reproduction: } 23(55 \%)\end{array}$} & \multicolumn{2}{|c|}{$\begin{array}{l}\text { Copy: } 31(30 \%) \\
\text { Immediate reproduction: } 22(55 \%)\end{array}$} \\
\hline $\begin{array}{l}\text { Judgement of line } \\
\text { orientation test } \\
\text { (total score }=30)\end{array}$ & \multicolumn{2}{|l|}{$20\left(22^{\text {nd }}\right.$ percentile $)$} & \multicolumn{2}{|l|}{$20\left(22^{\text {nd }}\right.$ percentile $)$} \\
\hline $\begin{array}{l}\text { Facial recognition test } \\
\quad(\text { total score }=54)\end{array}$ & \multicolumn{2}{|l|}{37 ( $4^{\text {th }}$ percentile) } & \multicolumn{2}{|l|}{$45\left(22^{\text {nd }}\right.$ percentile $)$} \\
\hline
\end{tabular}

* References for neuropsychological tests can be found in standard texts. ${ }^{56}$

cognitive difficulties persist. Repeat neuropsychological testing six months after operation was without change except she now scored in the moderate range of depression on the Beck depression inventory. ${ }^{7}$

CASE 2

A 31 year old woman was referred for evaluation of poor organisational skills and chronic depression refractory to psychotherapy and pharmacological intervention. She was noted to drag her right leg when she was about 18 months old and was diagnosed with cerebral palsy. She did well in all academic subjects except for mathematics, which she failed in the fourth grade. She reported severe depression since early childhood. Her family described her as "introverted" and having a "reserved personality".

She was noted to have a depressed affect and to avoid direct eye contact. Her speech was monotonic, slow, and measured.
Axial (left) and coronal (right) double echo MRI showing atrophy of the left temporal lobe and dilatation of the left temporal horn tip.
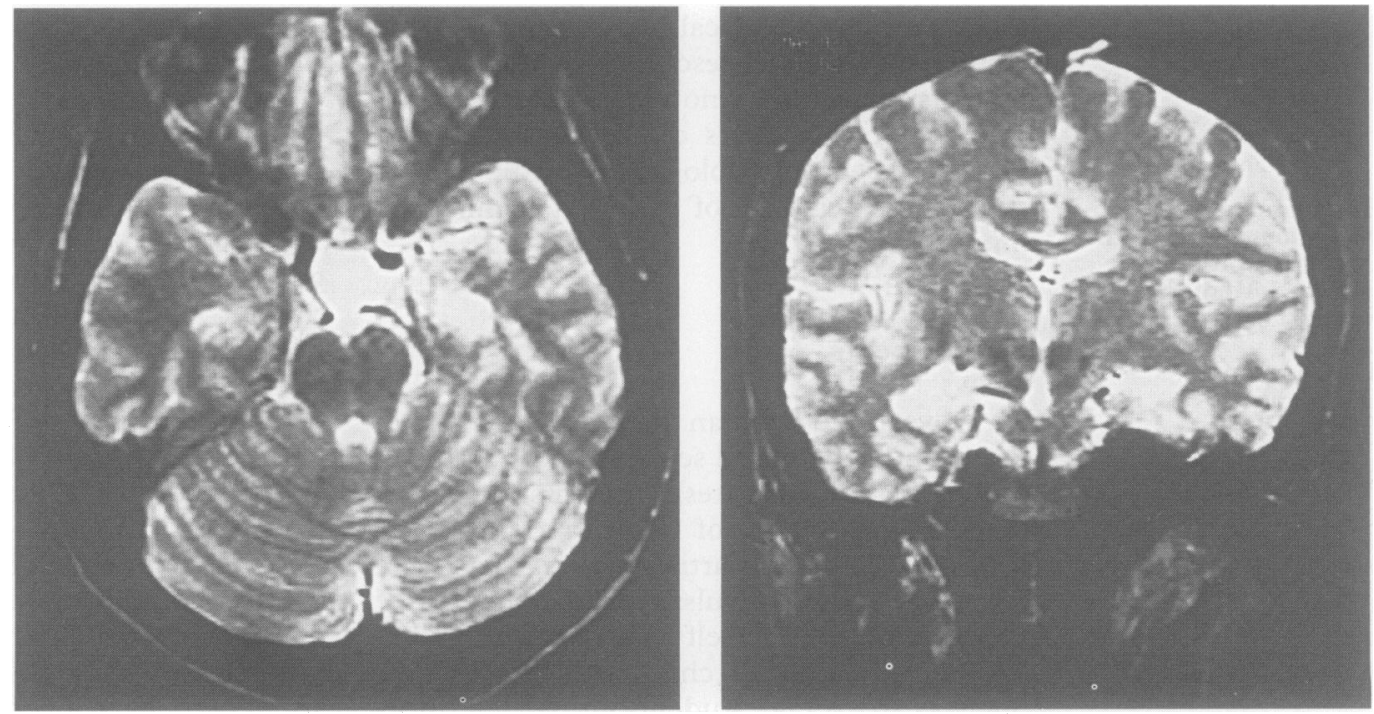
Gestures and body language were restricted. Neuropsychological evaluation (table) showed a 28 point discrepancy between verbal IQ ( $70^{\text {th }}$ percentile) and performance IQ ( $9^{\text {th }}$ percentile) as measured by the WAIS-R. There was increased vulnerability to interference on the Stroop color interference test. Dichotic listening for digits showed a left ear advantage $(83.3 \%$ correct for digits presented to the left ear $v 66.7 \%$ correct for the right ear). Memory testing showed mild difficulty encoding non-verbal information. Language functions were normal. Visuospatial perception and constructions were impaired. Her copy of the Rey-Osterreith complex figure was distorted and drawn in a piecemeal fashion. The interpretation of non-verbal facial expression and body gesture was formally assessed with the audio and video brief exposure portions of the profile of non-verbal sensitivity ${ }^{8}$ and was very impaired.

Neurological examination showed right hemihypoplasia involving the leg more than the arm. The right foot was $1 \frac{1}{2}$ shoe sizes smaller than the left. There was a mild right hemiparesis with increased deep tendon reflexes and an extensor plantar response.

An EEG showed brief paroxysmal non-sustained spike and spike slow wave activity from the left midtemporal region. A second EEG was normal. The left hemisphere was shown to be smaller than the right by CT.

\section{Discussion}

We describe two female patients with early left hemisphere injury and a developmental syndrome consistent with SEPD. Both patients described a lifelong history of deficient interpersonal relations and chronic depression refractory to pharmacological and psychotherapeutic interventions. Both patients had considerable difficulty with mathematics in school. On formal neuropsychological examination, visuospatial skills and paralinguistic aspects of communication were impaired. Unlike previously described cases of SEPD, however, neurological examinations and neurodiagnostic studies were consistent with left hemisphere injury. Both patients had right sided hemihypoplasia and right sided motor findings. EEGs showed left temporal epileptiform activity and neuroimaging studies left hemisphere abnormalities. Also, intracarotid amobarbitone testing showed normal language after left hemisphere suppression in case 1. Dichotic listening showed a left ear advantage for digit perception suggesting possible anomalous dominance for language in case $2 . .^{9}$ Both patients were left handed without a family history of non-righthandedness.

SEPD is a developmental syndrome characterised by $(a)$ interpersonal and emotional difficulties including extreme shyness, social isolation, and chronic, refractory depression, (b) abnormal interpretation and production of paralinguistic communication with avoidance of eye contact, flat or atypical speech prosody, and diminished or exaggerated facial expression and body gestures, and (c) impaired visuospatial skills with average to superior verbal abilities. ${ }^{2}$ Whereas there is a high incidence of difficulty with arithmetic, several patients have excelled in abstract mathematics. ${ }^{2}$ The discrepancy between our patients' normal performance on the arithmetic section of the WAIS-R and poor performance on the WRAT arithmetic may be related to the WAIS-R being a test of mental calculations whereas the written WRAT may be more sensitive to spatial acalculia.

Unlike the relation between left hemisphere abnormalities and dyslexia, which has been suggested on the basis of neuroanatomical and functional neuroimaging studies, ${ }^{1011}$ there is little direct evidence linking SEPD to right hemisphere dysfunction. Rudel and Denckla first described the association between SEPD and left sided neurological findings. ${ }^{12}$ Voeller found features of SEPD in 15 children who had evidence of right hemisphere injury by CT or neurological examination. ${ }^{3}$ Grace and Malloy reviewed records from 252 patients at a psychiatric hospital and found 12 patients who met their criteria for right hemisphere learning disability. Three of these patients had right hemisphere abnormalities on EEG and two had right hemisphere abnormalities on CT. ${ }^{13} \mathrm{We}$ have described six patients with SEPD and right hemisphere abnormalities on electrophysiological studies. ${ }^{4}$

There are at least four possible explanations for the paradoxical association of SEPD and early left hemisphere injury. First, undetectable right hemisphere damage could be present. A second possible explanation is that injury or epileptiform activity in one hemisphere can exert "abnormal influences" on the remaining hemisphere. ${ }^{14}$ This theory has been invoked to explain the improvement in cognitive functioning that is sometimes seen after hemispherectomy. A third possibility is that there could have been reversed cerebral dominance for all cognitive functions before any injury. In this case, early left hemisphere injury alone could result in SEPD. It is not possible to exclude any of these explanations. The first explanation seems unlikely because language would have to develop normally in a damaged right hemisphere. No improvement was seen in any aspect of SEPD in case 1 after left temporal lobectomy as might be expected if the second explanation were correct. The third explanation also seems unlikely as the right hemisphere is usually dominant for directed spatial attention and visuospatial skills even in patients with anomalous dominance for language or handedness. ${ }^{15} 16$

Finally, it is possible that early left hemisphere injury resulted in displacement of language and hand preference to the right hemisphere and that this reorganisation interfered with the development of cognitive, interpersonal, and emotional functions normally subserved by the right hemisphere. Experimental animal studies have shown that neural reorganisation after early brain injury 
can result in the sparing of some functions at the expense of others. ${ }^{1718}$ In humans, the sequelae of focal brain lesions is influenced by the age and developmental stage at the time of the injury, and early injury may result in considerable sparing of cognitive functions. ${ }^{1920}$ Little is known about the neuroanatomatical substrate of spared cognitive functions associated with early unilateral lesions in humans. It is possible that remodelling takes place analogous to that seen in experimental animals and that these changes interfere with the development of functions that these structures normally subserve. In this way, early left hemisphere injury in our patients could have resulted in pathological left handedness, anomalous dominance for language and "crowding" of the right hemisphere, which resulted in SEPD. The full syndrome of SEPD seems to be an uncommon manifestation of early left hemisphere injury. The "crowding" phenomenon may explain the more common association of early left hemisphere injury and neuropsychological profiles usually ascribed to right hemisphere dysfunction.

We thank M Marsel Mesulam, MD for reviewing the manuscript and for helpful comments.

1 Denckla MB. Minimal brain dysfunction. In: Chall J, Mirsky A, eds. Education and the brain. Chicago: National Society for the Study of Education and University of Chicago Press; 1978: chapter 7 .

2 Weintraub S, Mesulam MM. Developmental learning disabilities of the right hemisphere. Emotional, interpersonal, and cognitive components. Arch Neurol 1983;40: 463-8.
3 Voeller KKS. Right hemisphere deficit syndrome in children. Am f Psychiatry 1986;143:1004-9.

4 Manoach DS, Sandson TA, Mesulam MM, Price B, Weintraub $S$. The developmental social-emotional processing disorder is associated with right-hemisphere electrophysiological abnormalities [abstract]. $\mathcal{f}$ Clin Exp Neuropsychol 1993;14:56.

5 Weintraub S, Mesulam MM. Mental state assessment of young and elderly adults in behavioral neurology. In Mesulam MM, ed. Principles of behavioral neurology. Mesulam MM, ed. Principles of behavioral

6 Lezak M. Neuropsychological assessment. 2nd ed. New York: Oxford University Press; 1983:401,445.

7 Beck AT, Ward CH, Mendelsohn M, Mock J, Erbaugh J. An inventory for measuring depression. Arch Gen Psychiatry 1961;4:561.

8 Rosenthal R, Hall JA, DiMatteo MR, et al. Sensitivity to nonverbal communication: the PONS test. Baltimore: The Johns Hopkins University Press; 1979.

9 Geffen G, Caudrey D. Reliability and validity of the dichotic monitoring test for language laterality. Neuropsychologia 1981;19:413-23.

10 Galaburda AM, Sherman GP, Rosen GD, Aboitiz F Geschwind N. Developmental dyslexia: four consecutive patients with cortical anomalies. Ann Neurol tive patients with
1985;18:222-33.

11 Rumsey JM. The biology of developmental dyslexia. $7 A M A$ 1992;268:912-5.

12 Denckla MB. The Neuropsychology of social-emotional learning disabilities. Arch Neurol 1983;40:461-2.

13 Grace J, Malloy P. Neuropsychiatric aspects of right hemisphere learning disability. Neuropsychiatry, Neuropsycho Behav Neurol 1992;5:194-204.

14 McFie J. The effects of hemispherectomy on intellectua functioning in cases of infantile hemiplegia. $\mathcal{F}$ Neuro Neurosurg Psychiatry 1961;24:240-9.

15 Spiers PA, Schomer DL, Blume HW, et al. Visual neglect during intracarotid amobarbital testing. Neurolog 1990;40:1600-6.

16 Alexander MP, Fischette MR, Fischer RS. Crossed aphasias can be mirror image or anomalous: case reports, review and hypothesis. Brain 1989;112:953-73.

17 Schneider GE. Is it really better to have your brain lesion early? A revision of the "Kennard principle". Neuropsychologia 1979;17:557-83.

18 Kwok-Fai S, Schneider GE, Ayres S. Lesions of the brachium of the superior colliculus in neonatal hambrachium of the superior colliculus in neonatal hamsters: correlation of

19 Woods BT. The restricted effects of right-hemisphere lesions after age one; Wechsler test data Neuropsychologia 1980;18:65-70.

20 Rasmussen T, Milner B. The role of early left-brain injury in determining lateralization of cerebral speech functions. Ann N Y Acad Sci 1977;299:355-69. 